\title{
Fire and glint in AVHRR's channel 3: a possible reason for the non-saturation mystery
}

\author{
A. W. SETZER \\ INPE-C.P. 515-12201, São José dos Campos, SP, Brazil, and \\ Institute for Remote Sensing Applications, Joint Research Centre, \\ TP 440, I-21020 Ispra (VA), Italy \\ and M. M. VERSTRAETE \\ Institute for Remote Sensing Applications, Joint Research Centre, \\ TP 440, I-21020 Ispra (VA), Italy
}

(Received 9 July 1993; in final form 1 October 1993)

\begin{abstract}
Evidence from a very strong and rare case of sunglint in a NOAA-11 AVHRR image is used to show that a problem exists in the on-board signal processing of channel 3. This problem, associated only with targets of high reflectivity and/or temperature, causes erroneous indication of digital counts (DN) and calculated brightness temperatures for near-saturation ranges in channel 3 images. The explanation proposed, a spurious conversion of the sensor signal to DNs, fits observations of sunglint and fire detection data in AVHRR images of the NOAA-series satellites which could not otherwise be explained.
\end{abstract}

\section{Introduction}

Channel $3(3.55-3.93 \mu \mathrm{m})$ of the Advanced Very High Resolution Radiometer (AVHRR) on-board the NOAA-series satellites is sensitive to emitted as well as reflected energy in the optical spectrum. It supposedly saturates for Earth targets at about $47^{\circ} \mathrm{C}$, or $320 \mathrm{~K}$ (Kidwell 1991), and also with light from sunglint in water bodies (Khattak et al. 1991) or sun light reflected from some types of exposed soils (Grégoire et al. 1993). Snow, ice, and ice clouds, however, reflect relatively little in the channel 3 spectral region; most other clouds also reflect less than sunglint (Scorer 1989). According to Wien's displacement law, the thermal emission of vegetation fires in the range $400-700^{\circ} \mathrm{C}$ peaks in the $3-4 \mu \mathrm{m}$ range and calculations predict (e.g., Matson and Dozier 1981; Robinson 1991) that a fire of about $30 \mathrm{~m} \times 30 \mathrm{~m}$ in extent and near the centre of a channel 3 pixel should saturate it. This expectation is not supported by available measurements, however. For instance, large fires in forests and grasslands, sometimes occupying areas many times the size of an AVHRR pixel $(1.1 \times 1.1 \mathrm{~km}$ at nadir $)$ have been associated repeatedly with nonsaturated values of channel 3 (Belward et al. 1993, Pereira and Setzer 1993, Setzer and Malingreau $1993 \mathrm{a}$, Setzer et al. 1993). For sunglint no actual data are apparently found in the literaure. Brush (1993) showed an NOAA-12 AVHRR scene where the signal 'may' reach saturation; he also pointed to a 'transient' effect just entering the sunglint area, which will be easily explained with the new finding presented below. This transient signal, which appears in the channel 3 images like an atmospheric halo/corona effect around the sunglint area, whatever its size, as well as the non-saturation by very large fires may be the result of the on-board signal processing problem we believe to have found. This letter presents the evidence for our hypothesis. 


\section{Case description and discussion}

Figure I shows the NOAA-11 AVHRR image used, where Indo-China is on the west side and the Philippines on the east. Its contrast has been enhanced artifically just for illustration purposes and the data analysis was performed using the raw uncorrected data with full $1.1 \mathrm{~km}$ (nominal) and 10-but maximum resolutions. The sunglint area in the South China Sea is shown in red. This image was recorded during orbit number 07698 , with an ascending equatorial crossing of approximately 06:03 hours GMT and $121^{\circ} \mathrm{W}$, and downloaded at Wallops Island, VA, USA. The sunglint in the image occurred at a scan angle of about $23^{\circ}$. Such specular reflection is commonly observed when the Sun is near the AVHRR's scanning plane. Uncommon in the image is the small sunglint region in the north Borneo coastline. Figure 2 shows an enlargement of the relevant area, in the centre of Brunei Bay, at $5 \mathrm{~N}$ and $115^{\circ} \mathrm{W}$. The unusual characteristic of this small spot of sunglint is its

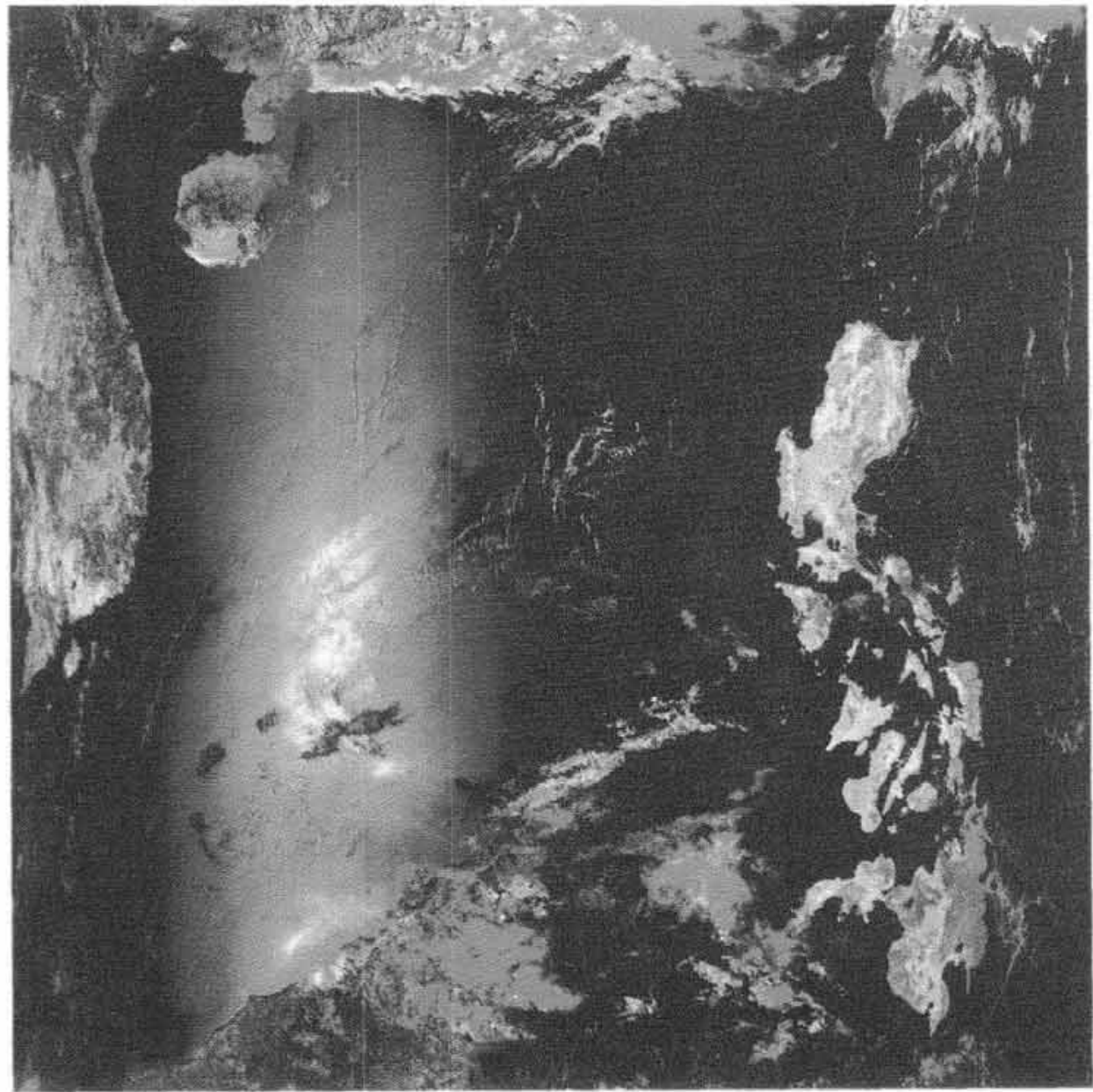

Figure 1. Raw AVHRR false-colour composite image showing sunglint in the South China Sea. Indo-China and the Gulf of Tonkin with Hai-Nan island are seen in the upper left corner; the Philippines are in the right side and Borneo in the lower side, 


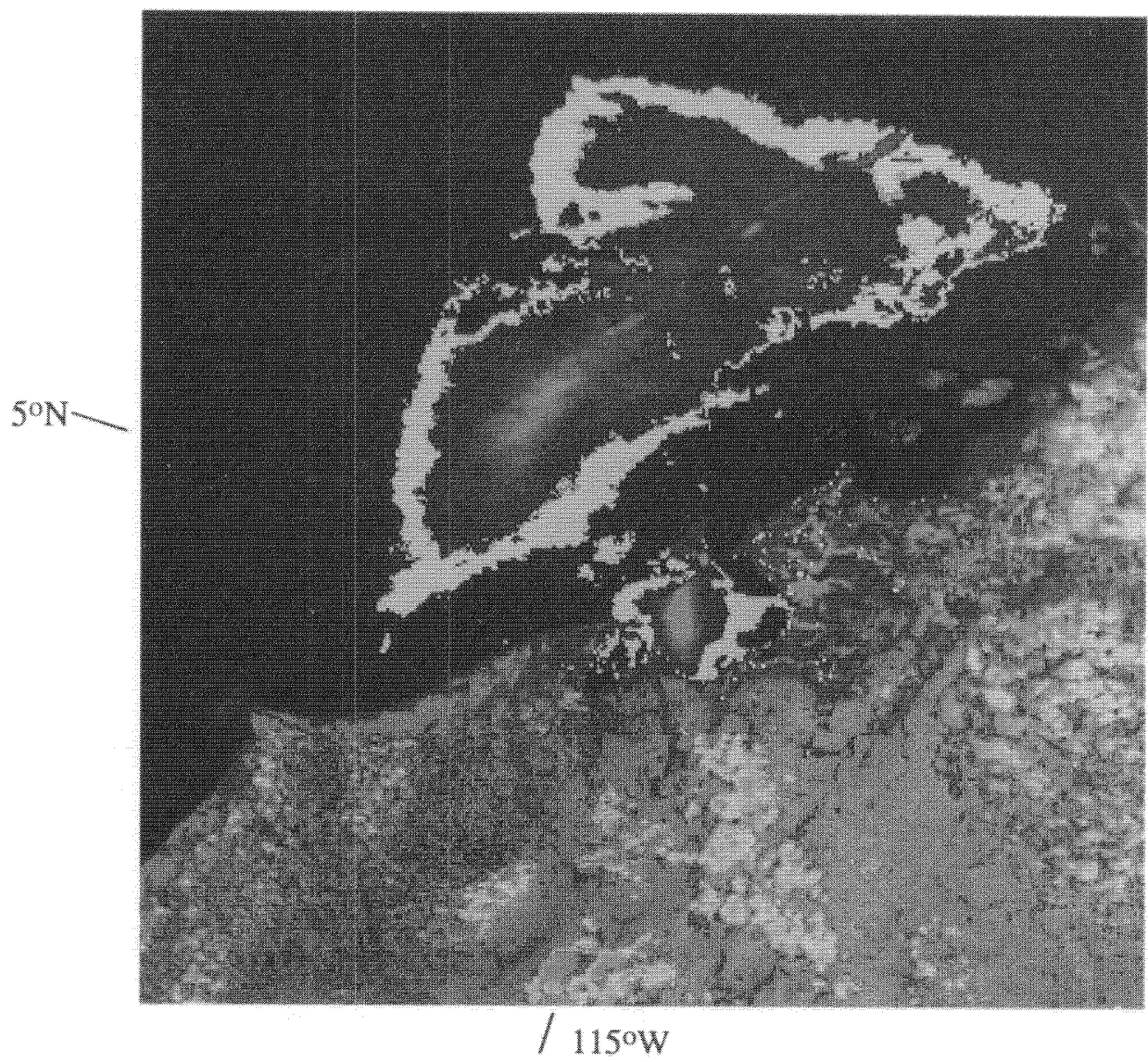

Figure 2. Very strong sunglint in the Brunei Bay at $5^{\circ} \mathrm{N}$ and $115 \mathrm{~W}$, in the north coast of Borneo. Note balo" effect in red colour surrounding also the larger and less intensive sunglint further north.

intensity, which can be analyzed from figure 3. This figure shows the digital counts (DN) of individual raw pixels in the original 0-1023 (10-bit) scale, for channels 1 to 4. for an area of $15 \times 15$ pixels with the sunglint at its centre. A saturated pixel with DN 1023 is found in channel $1(0.55-0.68 \mathrm{~mm})$ see figure $3(a)$, and another with DN $100 \%$, i.e., close to saturation, is lound in channel $2(0.751 .1 \mu \mathrm{m})$ see figure 3(b). In these two channels most pixels at the core of the sunglint, in the shaded area, have DNs above 700 and this is what makes the case unusual: nomally, sunglint is associated with DNs in the $200-400$ range, only rarely reaching the $600^{\circ}$ or higher. Unquestionably, this is a case of "metallic rellection from a water surface" using Scorer"s (1989) terminology. The explanation for such high reflectance is likely to be the absence of waves (K hattak et al. 1991) in the wind protected waters of a closed bay.

An extreme case of sunglint such as this one should have saturated channel 3 also, but this is not observed. Channel $3 \mathrm{DNs}$ in figure $3(\mathrm{c})$ are shown in their natural inverted scale, where saturation corresponds to 0 and very low temperature reflectiviy to 1023. We observe that the core of the sunglint is represented by pixels 
Channel 01

\begin{tabular}{|c|c|c|c|c|c|c|c|c|c|c|c|c|c|c|c|}
\hline & 77 & 78 & 79 & 30 & 81 & 582 & 583 & 584 & 585 & 586 & 587 & 588 & 589 & 990 & 591 \\
\hline 945 & 229 & 33 & 40 & 43 & 249 & 263 & 312 & 02 & 01 & 90 & 386 & 331 & 297 & 284 & 270 \\
\hline 946 & 236 & 238 & 246 & 254 & 268 & 304 & 375 & 497 & 653 & 554 & 404 & 337 & 308 & 289 & 271 \\
\hline 2947 & 245 & 246 & 255 & 267 & 292 & 31 & 421 & 701 & 336 & 40 & 395 & 339 & 308 & 84 & 272 \\
\hline 2948 & 253 & 259 & 268 & 287 & 309 & 347 & 576 & .1023 & 918 & 77 & 419 & & 09 & 83 & 269 \\
\hline 2949 & 259 & 268 & 81 & 02 & 331 & 449 & 908 & 972 & 830 & 508 & 447 & 359 & 10 & 85 & 270 \\
\hline $\begin{array}{l}2950 \\
2951\end{array}$ & $\begin{array}{l}258 \\
262\end{array}$ & $\begin{array}{l}273 \\
279\end{array}$ & $\begin{array}{l}295 \\
296\end{array}$ & $\begin{array}{l}319 \\
319\end{array}$ & $\begin{array}{l}368 \\
380\end{array}$ & $\begin{array}{l}644 \\
696\end{array}$ & $\begin{array}{l}982 \\
973\end{array}$ & & $\begin{array}{l}623 \\
794 \\
\end{array}$ & & & & $\begin{array}{l}322 \\
325\end{array}$ & $\begin{array}{l}290 \\
296\end{array}$ & $\begin{array}{l}276 \\
280\end{array}$ \\
\hline 2952 & 266 & 277 & 296 & 326 & 411 & 775 & 998 & 953 & 932 & 62 & 419 & & 13 & 93 & 279 \\
\hline 2953 & 261 & 281 & 307 & 355 & 458 & 717 & 1003 & 1013 & 910 & 14 & 443 & 366 & 22 & 297 & 284 \\
\hline 2954 & 263 & 277 & 295 & 31 & 390 & 587 & 842 & 917 & 878 & 100 & 486 & 393 & 37 & 305 & 280 \\
\hline $\begin{array}{l}2955 \\
2956\end{array}$ & & & & & $\begin{array}{l}359 \\
356\end{array}$ & & & 95 & & & & & $\begin{array}{l}42 \\
42\end{array}$ & & \\
\hline 2957 & 241 & 258 & 276 & 305 & 345 & 417 & 527 & 629 & 666 & 622 & 520 & 415 & 58 & 24 & 294 \\
\hline 2958 & 240 & 261 & 284 & 307 & 327 & 355 & 458 & 590 & 625 & 301 & 508 & 412 & 52 & 15 & 289 \\
\hline 2959 & 245 & 265 & 288 & 29 & 313 & 337 & 392 & 493 & 621 & 39 & 514 & 400 & 339 & 312 & 291 \\
\hline \multicolumn{16}{|c|}{ Channel 02} \\
\hline$|x|$ & 577 & & & & 81 & & 583 & & & & & & 9 & & 591 \\
\hline 2945 & 19 & 201 & 20 & & 215 & 227 & 271 & & & & & & 56 & 43 & \\
\hline 2946 & 203 & 204 & 212 & 219 & 232 & 264 & $\sqrt{328}$ & 435 & 566 & 477 & 347 & 290 & 264 & 248 & 232 \\
\hline 2947 & 211 & 212 & 220 & 231 & 253 & 290 & 370 & 12 & 717 & 464 & 340 & 291 & 264 & 244 & 233 \\
\hline 2948 & 219 & 224 & 232 & 249 & 269 & 306 & 508 & 895 & 796 & 493 & 358 & 306 & 265 & 242 & 230 \\
\hline 2949 & 223 & 232 & 243 & 264 & 290 & 397 & 797 & 974 & 721 & 525 & 384 & 308 & 266 & 243 & 231 \\
\hline 2950 & 222 & 236 & 256 & 278 & 325 & 572 & 963 & 78 & 53 & 0 & 37 & 322 & 275 & 20 & 236 \\
\hline 2951 & 226 & 24 & 258 & 27 & 337 & 620 & 979 & 95 & 67 & 430 & 35 & 310 & 279 & & 240 \\
\hline 2952 & 230 & 240 & 258 & 284 & 365 & 686 & 953 & 100 & 800 & 478 & 357 & 300 & 268 & 250 & 238 \\
\hline 2953 & 225 & 242 & 268 & 309 & 402 & 636 & 880 & 925 & & 522 & 377 & 312 & 275 & 253 & 242 \\
\hline 2954 & 223 & 236 & 253 & 285 & 340 & 517 & 736 & 802 & 759 & 597 & 414 & 336 & 288 & 260 & 245 \\
\hline 2955 & 216 & 221 & 23 & 25 & 310 & 428 & 586 & & & & & & 92 & & 24 \\
\hline & 20 & & & & & & & & & & & & 31 & & 248 \\
\hline 2957 & 201 & 216 & 232 & 258 & 294 & 58 & 454 & 14 & 5 & 33 & 442 & 352 & 05 & 276 & 249 \\
\hline 2958 & 196 & 215 & 236 & 258 & 276 & 304 & 395 & 509 & 39 & 516 & 434 & 351 & 299 & 268 & 245 \\
\hline 2959 & 197 & & & & & & & & & & & & 90 & & 248 \\
\hline \multicolumn{16}{|c|}{ Channel 03} \\
\hline$|x|$ & 577 & & & & & & & & & & & & & & 591 \\
\hline 2945 & 2 & 25 & 30 & 3 & 36 & 38 & 42 & & & 43 & 43 & 42 & 41 & 40 & 3 \\
\hline 2946 & 2 & 29 & 34 & 37 & 39 & 42 & 43 & & & 43 & 43 & 42 & 42 & 41 & 39 \\
\hline 2947 & 3 & 35 & 37 & 39 & 41 & 42 & 43 & 44 & 44 & 43 & 43 & 42 & 42 & 41 & 40 \\
\hline 2948 & 3 & 38 & 39 & 41 & 42 & 43 & 43 & 45 & 45 & 43 & 43 & 43 & 42 & 40 & 39 \\
\hline 2949 & 38 & 39 & 40 & 42 & 42 & 43 & 45 & 45 & 44 & 43 & 43 & 43 & 42 & 41 & 39 \\
\hline 2950 & 3 & 40 & 4 & 42 & 43 & 44 & 45 & 4 & 43 & 43 & 43 & 43 & 42 & 41 & 40 \\
\hline 2951 & & 4 & & & & 44 & 45 & & & 43 & 43 & 43 & 42 & & $4 c$ \\
\hline 2952 & 39 & 40 & 41 & 42 & 4 & 44 & 45 & 4 & 44 & 43 & 43 & 42 & 42 & 4 & 40 \\
\hline 2953 & 38 & 40 & 42 & 43 & 43 & 44 & 45 & 45 & 44 & 43 & 43 & 43 & 42 & 41 & 40 \\
\hline 2954 & 38 & 40 & 41 & 42 & 4 & 43 & 44 & 4 & 45 & 44 & 43 & 43 & 42 & 42 & 41 \\
\hline 2955 & 36 & 37 & 40 & & & 4 & 44 & & & 4 & 3 & 4 & 42 & & 4 \\
\hline 2956 & 32 & 36 & 4 & & 4 & & 43 & & & 44 & 43 & 43 & 42 & 42 & 41 \\
\hline & 28 & 36 & 3 & & 4 & & 43 & & & & & 43 & 43 & 42 & 4 \\
\hline 2958 & 21 & 35 & 40 & & 42 & 43 & 43 & & & 43 & 43 & 43 & 42 & 42 & 41 \\
\hline 959 & 26 & 35 & 40 & 1 & 42 & 4 & 43 & 43 & 43 & 44 & 43 & 43 & 42 & 42 & \\
\hline
\end{tabular}

Chennel 04

\begin{tabular}{|c|c|c|c|c|c|c|c|c|c|c|c|c|c|c|c|}
\hline$\perp x$ & 577 & 78 & 579 & 580 & 581 & 582 & 583 & 584 & 585 & 586 & 587 & 588 & 589 & 590 & 591 \\
\hline 945 & 385 & 385 & 383 & 382 & 382 & 382 & 381 & 380 & 379 & 379 & 379 & 379 & 379 & 380 & 381 \\
\hline 946 & 383 & 83 & 81 & 380 & 381 & 380 & 378 & 378 & 78 & 378 & 379 & 379 & 380 & 381 & \\
\hline 347 & 381 & 81 & 80 & 380 & & 378 & & & & & & & & & \\
\hline 948 & 380 & 80 & 380 & 379 & 377 & & & 77 & & & 381 & & & & \\
\hline 949 & 380 & 380 & 379 & 378 & 377 & 5 & & & & 0 & & 380 & 80 & & \\
\hline 950 & 379 & 37 & & & 37 & & & & & & 37 & 380 & 380 & 79 & 38 \\
\hline 951 & 37 & & & & & 31 & & & & & & & 31 & 80 & 38 \\
\hline 352 & 379 & 3 & & & & 37 & & & & & 38 & 2 & 382 & 81 & \\
\hline 53 & 378 & 78 & & 37 & 37 & 376 & 376 & 377 & 178 & 379 & 38 & 31 & 381 & & \\
\hline 954 & 377 & 76 & & & 7 & 376 & 376 & 376 & 176 & 7 & 8 & 8 & 379 & 79 & \\
\hline 955 & 378 & & & & & 178 & 377 & 8 & & 8 & & 8 & 378 & 379 & \\
\hline 956 & 379 & & & & & & & & & & & & 378 & 79 & 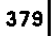 \\
\hline 957 & 380 & 79 & & 378 & 378 & 378 & 378 & 379 & 881 & 381 & 38 & & 379 & 79 & 7 \\
\hline 958 & 379 & 379 & 378 & 378 & 378 & 377 & 378 & 380 & 381 & 38 & 382 & 380 & 379 & 179 & 37 \\
\hline 959 & 376 & 376 & 376 & 377 & 378 & 378 & 377 & 379 & 381 & 383 & 382 & 381 & 380 & 379 & 37 \\
\hline
\end{tabular}

Figure 3. AVHRR digital counts (DNs) for pixels in the centre of intense sunglint. See table 1 for the limits of classes used for channels 1 to 3 . 
with a DN 45 instead of the expected value of zero. We further observe from figure 3 that the signal in channel 3 is positively correlated to the signals of channels 1 and 2 . Therefore, surprisingly, the reflectance/temperature signal in channel 3 increases (lower DNs on the inverted scale) outwards from the sunglint while the reflectance decreases in the visible and near IR channels. The DN ranges for channels 1 and 2, associated with DN values of $45-41$ in channel 3 for the data subset shown in figure 3, are listed in table 1. DNs of channels 1 and 2 for the corresponding channel 3 DNs of 46 to 49 found outside the intense sunglint inverted this trend and were in the following ranges, respectively: 195 to 200 , and 168 to 170 .

Figure 4 shows the profiles of pixel values for all 5 channels for a segment of an AVHRR scan line (2952 in figure 3 ) passing through the core of the sunglint. The peaks of channels 1 and 2 coincide and indicate unambiguously the core of the sunglint where they reach values at or close to saturation. Channels 4 and 5 , on the other hand are not sensitive to reflected sun light and show no noticeable variation in the core of the sunglint area. This implies that the sea surface temperature must have been essentially constant throughout the area. Using calibration coefficients provided with the data, the nominal temperature for the area of figure 3 was close to $23^{\circ} \mathrm{C}$ and the variation was only a few tenths of one degree $\mathrm{C}$. The interesting finding is that the curve for channel 3 reaches saturation at two other places, away from the core of the sunglint, at totally unexpected places.

This finding could however be explained by a faulty on-board conversion of the analogue signal from the channel 3 sensor into DNs. This conversion should in principle take place monotonically, i.e., associate progressively lower DNs to increasing radiance measurements. Instead, we postulate that beyond a specific threshold radiance, increasing radiances are transformed into increasing DNs. In this type of curve, schematically shown in figure 5, a signal level higher than the level corresponding to a null DN results in DNs previously allocated to lower signal levels. Therefore, in figure 4 we believe that the correct curve for channel 3 should be a kind of mirror image with respect to the $x$ axis for those pixels situated in the interval between the pixels where saturation is first reached.

The areas with a DN of zero are shown with a red tone in figure 2 and can be found surrounding the sunglint regions following the pattern of the graph in figure 4. In addition to the Brunei Bay, another and larger sunglint to the north can be seen in the same figure, but presenting DNs in channels 1 and 2 in the common ranges below 400. This edge effect with pixels of zero DN, which gives the impression of a corona/halo/transient effect, is easily explained as resulting from a signal conversion curve like the one in figure 5. We also want to emphasize that this edge effect of

Table 1. Class ranges in the core of the intense sunglint.

\begin{tabular}{ccc}
\hline Channel 3 & Channel 12 & Channel 2 \\
\hline 45 & $>878$ & $>759$ \\
44 & $622-877$ & $533-758$ \\
43 & $347-621$ & $304-532$ \\
42 & $302-346$ & $260-303$ \\
41 & $285-301$ & $243-259$ \\
40 & $272-284$ & $233-242$ \\
\hline
\end{tabular}




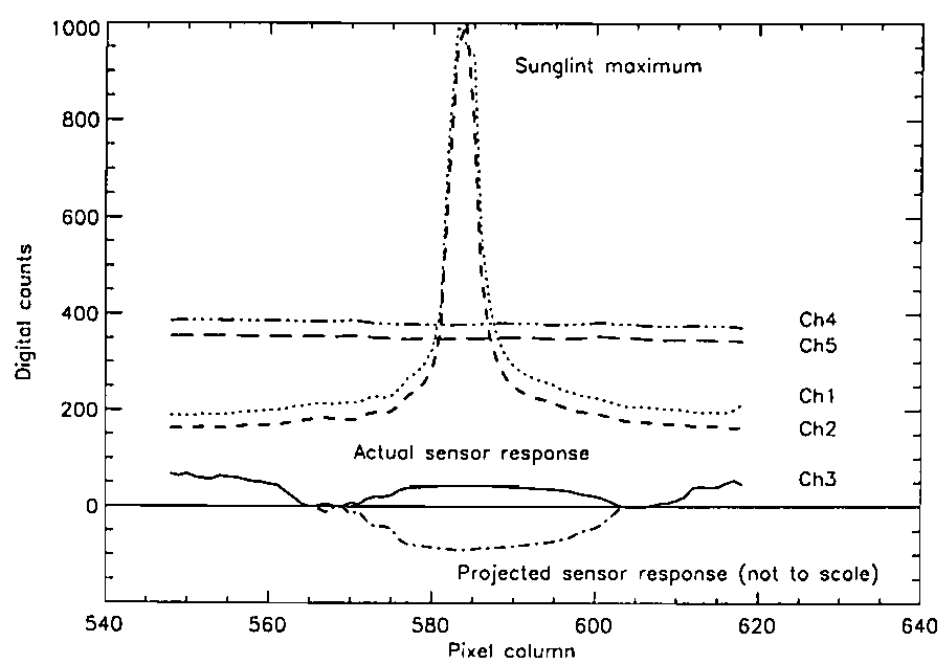

Figure 4. Line transect through an intense sunglint in an AVHRR image. Actual pixel values for the central part are found in figure 3, line 2952.

channel 3 was found not only in the two cases shown in figure 2, but also in all other cases of sunglint in dozens of NOAA-11 AVHRR channel 3 images we have examined.

This interpretation of anomalous data can be confirmed independently by analyzing data from an entirely different process, namely fire detection over continents in AVHRR channel 3 images. Vegetation fires, no matter their temperature or size, provided the fire front is larger than $\sim 50 \mathrm{~m}$, do not saturate channel 3 (Belward et al. 1993, Pereira and Setzer 1993, Setzer and Malingreau $1993 \mathrm{a}$, Setzer et al. 1993), contrary to calculations based on the emitted energy (e.g.,

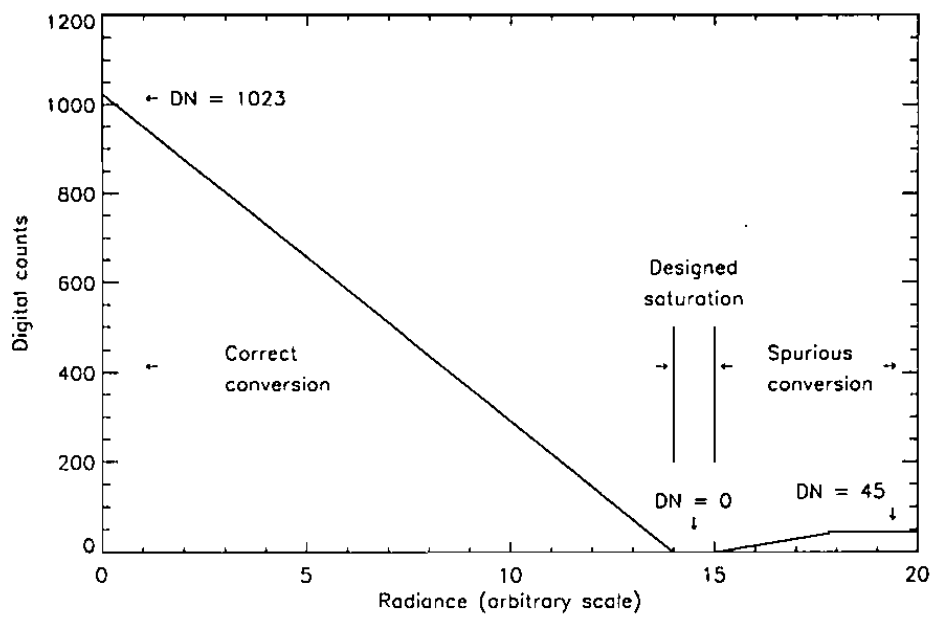

Figure 5. Hypothetical channel 3 conversion of radiance into digital counts. 
Matson and Dozier 1981; Robinson 1991). Furthermore, actively burning fires were consistently associated with a DN of 45 in channel 3 during March, 1990 (Setzer and Malingreau $1993 \mathrm{a}, \mathrm{b}$, precisely the same value found in the core of our exceptional sunglint. When examining histograms of channel 3 images containing many fires or sunglint a very steep change in their profiles was regularly found at DN 45 indicating a discontinuity at this point. We conclude that our postulated engineering problem would also explain why hot fires over continents do not saturate channel 3 pixels. This could further imply that AVHRR channel 3 may actually be observing much higher temperatures than currently estimated on the basis of existing data, calibration coefficients and established calibration procedures given by Kidwell (1991). Finally, the fact that at least NOAA-9 AVHRR exhibited the same pattern of nonsaturation of channel 3 over active fires (Pereira and Setzer 1993, Setzer and Pereira 1991) suggests that the same problem may affect multiple AVHRR instruments; histogram discontinuities for fire pixels in NOAA-9 AVHRR similar to what we found for NOAA-11 AVHRR can be seen in Brustet et al. (1991) and Pereira and Setzer (1993).

\section{Conclusion}

Our observation of particular DN values associated with targets which should, but do not saturate AVHRR's channel 3 is corroborated with analyses of a large number of AVHRR scenes both over oceans (sunglint) and continents (sunglint and fires). Our claim concerning a possible design flaw in the instrument circuitry could be confirmed by a thorough evaluation of the instrument. As far as channel 3 users are concerned, estimates of fire temperatures and sunglint energy becomes now a valid exercise combining a proposition along the pattern of figure 5 with the multispectral information of AVHRR from existing fire and sunglint data-an attractive possibility to extend the channel 3 range to $500^{\circ} \mathrm{C}$ or more. Unfortunately, highly reflective exposed soils in some cases will also have the same DN signal as fires in the defective AVHRR images, precluding a general application of AVHRR's image in fire monitoring. As for the future AVHRRs, if our hypothesis is correct, two possibilities exist: either leave the sensor in its current condition and alert users of the problem, or make the 0-1023 digital range match the sensor output. A third option, the elimination of the signal after the currently designed saturation limit of $\sim 47^{\circ} \mathrm{C}$, would limit even more its use in such an important application as fire detection.

\section{Acknowledgment}

We acknowledge the support of the Brazilian Scientific Council (CNPq) which made the development of this work possible through grant no. 200602/79-9.

\section{References}

Belward, A. S., Grégoire, J. M., D'Souza, G., Trigg, S., Hawkes, M., Brustet, J. M., Serca, D., Tireford, J. L., Charlot, J. M., and Vuattoux, R., 1993. In-situ, real time fire detection using NOAA/AVHRR data. 6th European AVHRR Data Users' Meeting, Belgirate, Italy, 28 June-2 July. Italy, Proceedings, CEC/JRC, Ispra, Italy, in press.

BRush, R. J. H., 1993. Anomalous effect of sunglint on the AVHRR in the NOAA-12 satellite. International Journal of Remote Sensing, 14, 629-634.

Brustet, J. M., Vickos, J. B., Fontan, J., Manissadjan, K., Podaire, A., and lavenu, F., 1993. Remote sensing of biomass burning in West Africa with NOAA-AVHRR. In 
Global Biomass Burning, edited by J. S. Levine (Cambridge, Mass.: The MIT Press), pp. 47-52.

Grígolrl:, J. M., Belward, A. S., and Kennedy, P., 1993. Dynamiques de saturation du signal dans la bande 3 du senscur AVHRR: handicap majeur ou source d'information pour la surveillance de l'environnement en milieu soudano-guinéen d'Afrique de l'Oucst? International Journal of Remote Sensing, 14, 2079-2095.

Khattak, R. A., Vaughan, R. A., and Cracknell, A. P., 1991. Sunglint and its observation in AVHRR data. Remote Sensing of Environment, 37, 101-116.

KIDWlill, K. B., 1991. NOAA polar orbiter data user's guide. NOAA/NESDIS, Washington, D.C.

Matson, M., and Dozier, J., 1981, Identification of subresolution high temperature sources using thermal IR sensor. Photogrammetric Engineering and Remote Sensing, 47, $1311-1318$.

Perijira, M. C., and Setzer, A. W., 1993, Spectral characteristics of deforestation fires in NOAA/AVHRR images. International Journal of Remote Sensing, 14, 583-597.

Robinson, J. M., 1991. Fire from space: Global fire evaluation using infrared remote sensing. International Journal of Remote Sensing, 12, 3-24.

Scorer, R. S., 1989, Cloud reflectance variations in channel-3. International Journal of Remote Sensing, 10, 675-686.

Setzer, A. W., and Malingreau, J. P., 1993 a. Temporal variation in the detection limit of fires in AVHRR's ch. 3. 6th European AVHRR Data Users' Meeting. Belgirate, Italy, 28 June-2 July, Italy, $6 \mathrm{pp}$. CEC/JRC, Ispra, Italy, in press.

Serzer, A. W., and Malingreau, J. P., $1993 \mathrm{~b}$. AVHRR monitoring of vegetation fires in the tropics: towards a global product. Submitted to Remote Sensing of Environment.

Sizzer, A. W., and Pereira, M. C., 199I, Amazonia biomass burning in 1987 and an estimate of their tropospheric emissions. Ambio, 20, 19-22.

Sizzlir, A. W., Pereira, M. C., and Pereira JR., A. C., 1993, Satellite studies of biomass burning in Amazonia-some practical aspects. Remote Sensing Reviews, in press. 